\title{
Logistics and principles of use of solid and liquid household waste, as relevant energy resource
}

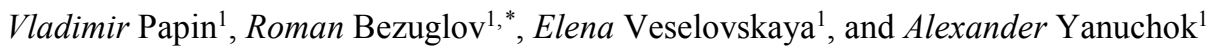 \\ ${ }^{1}$ Platov South-Russia State Polytechnic University (NPI), Department "Thermal Power Stations and \\ Heat Engineering", 346400 Novocherkassk, Russia
}

\begin{abstract}
The principles of effective management of the existing and again arriving waste of different types are considered in this article. Some enterprises of the Russian Federation are considered as sources and consumers of an energy resource. In addition to the main objective elimination of a large number of the saved-up waste, the task of extraction the useful materials for further use in necessary spheres of the industry is set. Development of heat and electrical energy. The solution of objectives will be carried out by development of the conceptual scheme of logistics the different types waste which will include a layered design with final recommendations for consumers and the enterprises. Also the complex analysis of waste on economic (to the principle of usefulness) and territorial to signs will be carried out.
\end{abstract}

\section{Introduction and problem definition}

One of the most current problems of the present is disposal of a large number the saved-up waste. This problem is especially relevant in the world and in our country. A relevance main points of a research:

- the volume of the organic waste which is annually getting on dumps of the Russian Federation is $15-20$ million tons;

- incomplete recycling;

- lack of communications in places of processing of waste.

However, the objective of this research puts not only elimination of waste, but also search of ways of their use. In particular it is necessary to use waste for development of heat and electrical energy and also for selection of useful substances and for other purposes, for example, the direction material on other objects, in particular, of construction materials.

The main objective of a research - elimination of a large number of the saved-up waste of different types - liquid, firm, gaseous, household, industrial, agricultural, organic and other types. In addition to the main solvable objective it is necessary to solve a problem of passing extraction of useful materials for further use in necessary spheres of the industry and also development of heat and electrical energy with exceeding of volume of the electric power going on own needs.

*Corresponding author: romanbezuglov@inbox.ru 


\section{The analysis of the last achievements and publications on a research subject}

\subsection{The existing main types and technologies of waste processing units}

The units for processing of a broad spectrum of waste presented at the Russian market (municipal solid waste, agricultural, containing rubber, plastics and others), it is possible to divide into 3 main groups:

- the pyrolysis units which are subdivided on:

- low-temperature installations $\left(\mathrm{T}=300-500{ }^{\circ} \mathrm{C}\right)$;

- high-temperature installations $\left(\mathrm{T}=500-1200^{\circ} \mathrm{C}\right)$;

- plasma installations (reactors) $\left(\mathrm{T}=2000-5000^{\circ} \mathrm{C}\right)$;

- burning installations:

- incinerators $\left(\mathrm{T}=1000-1300^{\circ} \mathrm{C}\right)$;

- burning of waste in slag fusion;

- other technologies:

- biothermal composting;

- hydrothermal destruction;

- anaerobic fermentation.

\subsection{The analysis of sources on a recycling subject}

Now the subject of power complexes quite actively progresses in scientific and technical literature as complex generation of energy from several sources gives high reliability of receipt of required amount of energy [1-6].

The similar situation is in the field of power complexes on recycling. Authors of this research carried out the analysis of scientific and technical sources on scope of utilization of different waste by different ways. Special attention was paid on installations of hydrothermal destruction and burning of waste in slag bathtubs. These technologies are considered as authors as the most attractive in terms of obtaining thermal and electric energy and useful materials in view of the following reasons:

- the maximum decrease in emissions of harmful substances is reached;

- there is a solution or fusion, the allowing electrolysis;

- at hydrothermal destruction it is possible to receive steam suitable for utilization in the steam turbine;

- the pyrolysis modes with receiving gaseous and liquid fuel are rather easily provided.

As for a method of hydrothermal destruction: authors [7] applied a method of supercritical hydrothermal destruction to neutralization of dangerous substances and resistant organic pollutants (the polychlorinated diphenyls, organochlorine pesticides, drain waters, waste of agro-industrial complex) in the auto-thermal and allotermic modes. Authors considered the possibility of utilization of potential energy of gaseous reaction products at the developed experimental stand of hydrothermal destruction on the basis of the multi-pipe reactor of the spiral scheme. This reactor is a part of an autonomous power complex, for production of heat and electrical energy.

In the publication [8] authors consider prospects of use of self-contained power stations on the basis of technology of supercritical hydrothermal destruction of biomass with receiving combustible gases for a solution of regional problems. In articles [9-11] different power complexes on processing of food and other types of waste for generation of heat and electrical energy are generally described. These installations are at an experimental stage, however have high potential and force to think that in the near future similar installations 
will be implemented even more often into power supply systems of the different enterprises.

Concerning the installations burning waste in slag bathtubs (fusion) it is possible to report the following. There are also practices on these researches in our country. In article [12] for electricity generation from coal and local low-grade fuels it is offered to use technology of gasification of fuel in the liquid slag fusion bubbled by blasting, enriched with oxygen. Process is carried out in the Furnace reactor of Vanyukov or Romelt. Process consists in intensive mixing in a blasting zone of the loading materials in slag fusion and full combustion of waste. High working temperature of process (1250-1350 $\left.{ }^{\circ} \mathrm{C}\right)$ prevents formation of dioxine in flue gases and slag and provides full combustion of a combustible part of municipal solid waste. At the same time are formed chemically resistant, uniform and strong slag. The most important advantages of waste processing technology in Vanyukov's furnace are the high specific performance caused by intensive hashing of a slag bathtub and also a process avtogennost (without fuel expenses).

Among intellectual property it is possible to note the following positions. «Way of processing of household and industrial wastes» [13]. This way consists in reburning of the allocated combustible components, dust utilization and heat of flue gases. A gas is supplied in fusion with a speed of expiration within 50-150 nanometers/sec. Enter ferriferous gumboil in the quantity necessary for maintenance of iron content in slag fusion within 10$15 \%$ into fusion. Advantage of this way is decrease in capital and energy consumption, increase in extraction of non-ferrous metals in products.

«Way of processing of the oxidic raw materials containing non-ferrous metals». This way consists in melting of oxidic raw materials in the presence of metal fusion and carboniferous reducer. Process is conducted in the electric furnace of a direct current in the presence in it layers of the metal and made foam slag oxidic fusions, the speed and extent of restoration of non-ferrous metals increases. In addition, electroexpenses decrease, degree of purity of the extracted metals raises [14].

Considering the aforesaid, it is possible to see that now there is a technological basis for creation of logistic structure of recycling in various ways and also passing allocation from them useful substances and/or production of thermal and electric energy.

\section{Development of the concept of power and raw logistics - use of various waste}

\subsection{Prerequisites for development of power and raw logistics}

Now in our country there is no technique and recommendations about optimum use of waste and their elimination. Also there are no recommendations about competent distribution of the useful materials emitted from waste. So, for example, it is possible to establish the overworking complexes to the place of formation of waste at the enterprise and, utilizing waste, to receive, for example, the useful metals directed further to the enterprise to other city.

The term "Power and Raw Logistics" is provided by authors. It means streams management of waste, information on volumes, structures and other their characteristics and also the system control of devices at the enterprises providing process of work with streams of waste, aimed at optimization of these streams and detection of various needs of objects for useful raw materials, electric and thermal energy and opportunities of their receiving.

All types of waste are considered in the context of a power and raw system, that is waste will be processed for allocation from it useful substances. It occurs in view of the fact that, 
for example, concentration of iron content in slags reaches $25 \%$, and in a heat and slime from production of ferrous metallurgy reaches $60 \%$ that many times over exceeds admissible norms on nonenriched ores. And all of them also contain impurity of flying metals, generally zinc (37\% in slags of the copper plants, $6-10 \%$ in lead). Waste from color metalproduction contains also $\mathrm{Cu}, \mathrm{Ni}, \mathrm{Co}$ and $\mathrm{Ar}$.

Main objectives of waste processing in this research put elimination of the saved-up and arriving waste and allocation and recycling of useful substances. At the same time power generation is the accompanying process which significantly is reducing the price of processing of waste.

The developed energy will be spent for own needs of installation on processings of waste, at the same time surplus will be sent to external network for power supply of consumers.

Within the research the analysis of volumes, structure and the geographic location of various types of waste in the Russian Federation and also the analysis of ways of their destruction or processing is supposed. Also definition a range of useful components which are possible for taking from waste of various types will be carried out.

The analysis of potential consumers needs, when processing waste and developing the principles of power and raw logistics at identification opportunities of use a waste will be the following investigation phase.

For obtaining applied result of researches it is also necessary to execute compliance between needs of consumers and opportunities of use a waste.

Further processing of collected data with use of the developed mathematical model of power and raw logistics will be made. The special case of realization of mathematical model of the developed power and raw logistics on the example of the Rostov region will be realized. Waste of one or several concrete enterprises and also needs of consumers both private, and industrial will be considered.

As a result of a research the technique the determination of power complexes structure, depending on such factors as territorial location of an object, structure and characteristics of waste, need of the nearby consumer for this or that product or a type of energy will be received.

The research assumes identification of certain regularities on formation of power and raw logistics in terms of power and economic feasibility.

\subsection{Schematic diagram of power and raw logistics}

The developed power and raw logistics assumes the organization of various blocks interaction. The schematic diagram of power and raw logistics (figure 1) includes four main sectors:

- sector of sources;

- analytical sector;

- sector of generation;

- sector of distribution.

The sector of sources assumes receipts of various types of waste from the $\mathrm{X}, \mathrm{Y}$ enterprises and also from grounds of waste. Further waste is sorted for the maximum use in the overworking power complexes.

The analytical sector means preprocessing of waste and includes such blocks as "Sorting of waste" and "Analysis". At a stage of the analysis there is a choice of the purpose of processing of waste - it is obtaining energy or release of useful raw materials.

Further in the sector of generation there are similar processes in the directions of power generation or release of useful raw materials. Each direction includes Slag Fusion and Hydrothermal Destruction blocks, in view of the reasons specified in Section 2.2. Further 
there is directly a process of power generation in a power complex and receiving useful raw materials.

In the following sector - the sector of distribution there is a distribution of the received thermal and electric energy and also the produced raw materials. Thermal energy can arrive on the industrial and private consumer, depending on its potential, requirement and distance to the consumer. Electric energy is spent for two types of receivers - own are necessary power complexes and processing of waste and/or on the enterprises (in this case, electric energy arrives on enterprise Y). The extracted useful raw materials can go also to the enterprises, in this case, on enterprise $\mathrm{Z}$. Waste which are completely processed are subject to elimination (for example, to burial).

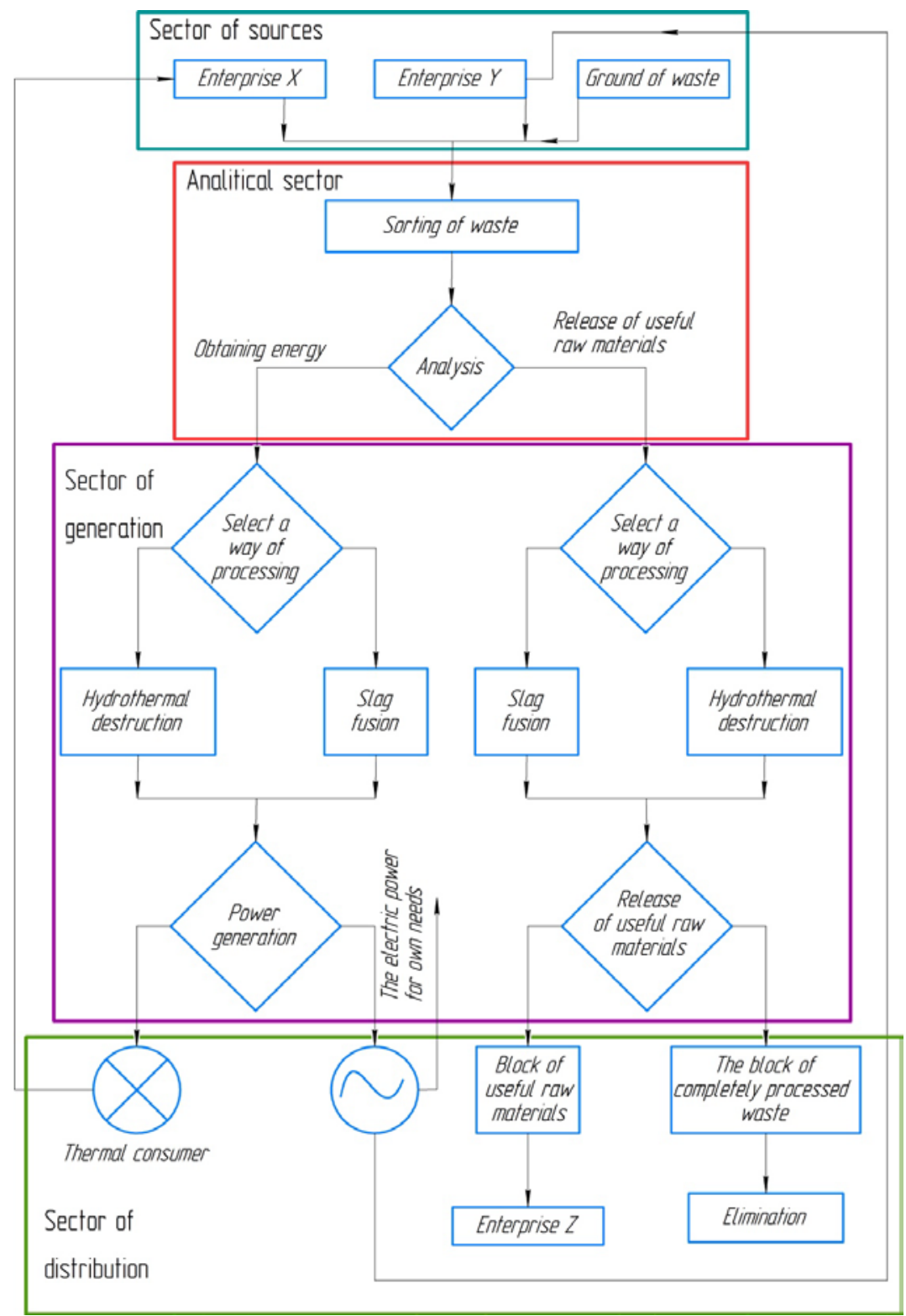

Fig. 1. Schematic diagram of power and raw logistics. 


\section{Conclusions}

Basic provisions of the research directed to elimination of the existing and again formed waste, with passing extraction of useful materials and/or development of thermal and electric energy are presented in this article. The schematic diagram of power and raw logistics on processing of waste is developed. The complex logistic concept of distribution, processing and recycling with accurate recommendations about each aspect of use a data, carrying out compliance between needs of consumers and opportunities use of waste will become result of this research.

Article is executed with assistance of a grant of the Russian Federation President to the young scientist and graduate students who are carrying out perspective research and development in the priority directions of modernization of the Russian economy for 2018-2020 (Project No. SP459.2018.1).

\section{References}

1. V.V. Papin, R.V. Bezuglov, V.N. Baltyan, Energy efficiency of the heat and power complex for highly efficient use of secondary and renewable energy resources, Material Science Forum, 2018. - Vol. 931, - P. 933-937.

2. V.V. Papin, R.V. Bezuglov. E.V. Veselovskaya, The test bench of a cascade heatpump installation of a heat power complex for highly effective use secondary and renewables, MATEC Web of Conferences. - 2018. - Vol. 224: ICMTMTE 2018. Access mode: https://doi.org/10.1051/matecconf/201822402056.

3. N.N. Efimov, V.V. Papin, R.V. Bezuglov. Micro Energy Complex Based on WetSteam Turbine / Procedia Engineering. Vol. 150 (2016), p. 324-329, http://dx.doi.org/10.1016/j.proeng.2016.07.022

4. R.K. Cheng, Low-Swirl Combustion-An Ultra-Low Emissions Technology for Industrial Heating \& Gas Turbines, and Its Potential for Hydrogen Turbines, Leader, Combustion Technologies Group Environmental Energy Technologies Div, Lawrence Berkeley National Laboratory Berkeley. 8 (2006).

5. V. L. Castaldo, A. L. Pisello, C. Piselli, C. Fabiani, F. Cotana, M. Santamouris, How outdoor microclimate mitigation affects building thermal-energy performance: A new design-stage method for energy saving in residential near-zero energy settlements in Italy / Renewable Energy, vol. 127, 2018, Pages 920-935, https://doi.org/10.1016/j.renene.2018.04.090

6. Y. Wang, C. Jiang, Y. Liu, D. Wang, J. Liu, The effect of heat and moisture coupling migration of ground structure without damp-proof course on the indoor floor surface temperature and humidity: Experimental study / Energy and Buildings vol. 158, 2018, Pages 580-594, https://doi.org/10.1016/j.enbuild.2017.10.064

7. Roshchin A.V., Grigoriev V.S., Sagittarius A.V., Nikolaev A.I., Rayevskaya E.G., Usin V.V., Supercritical hydrothermal destruction of the dangerous substances containing organic chemistry and waste with the prospect of utilization of energy potential of gaseous products, Chemical physics, V. 36, № 7, 2017, p. 18-24.

8. Artamonov A.V., Pashkin S.V., Fedotov A.V., Kozhevnikov Yu.A., The prospects of use of independent power stations on the basis of supercritical hydrothermal destruction of biomass for the solution of regional problems, Modern problems of engineering sciences, the collection of scientific works of the VI International scientific 
and technical Symposium "Modern power - and resource-saving technologies SETT 2017», 2017, p. 233-237.

9. Vedenin A.D., Mazalov D.Yu., Solovyov R.Yu., Strelets A.V., Fedotov A.V., Autonomous power complex on the basis of hydrothermal destruction of foodstuff and their waste, Quality and environmental safety of foodstuff and productions, Materials IV of the International scientific conference with elements of sciences school for youth, 2016, p. 3-6.

10. 10. Artamonov A.V., Pashkin S.V., Grigoriev V.S. and others, Supercritical water technologies for the solution of ecological and power tasks of agrarian and industrial complex, Bulletin of the Bashkir state agricultural university, 3 (47), 2018, p. 7-12.

11. Astafyev M.M., Vedenin A.D., Konstantinovskaya M.V., Mazalov D.Yu., Milovanov N.S., Sorokovikov A.I., Feoktistov A.I., Design of the hydrothermal reactor of an autonomous power complex, Innovations in agriculture, 5 (20), 2016, p. 294-299.

12. Paretsky V.M., Kamkin R.I., Kuznetsov A.V., Mamayev A.Yu., Kamkin S.I., Burning of waste in slag fusion, Municipal solid waste, 9 (39), 2009, p. 34-39.

13. Rusakov M. R., Simonov M.D., Way of processing of household and industrial wastes, patent of the Russian Federation for an invention №2349654, F23G5, C22B7.

14. Leontyev V.G., Bryukvin V. A., Panfilov S.A., Paretsky V.M., Tarasov A.V., Way of processing of the oxidic raw materials containing non-ferrous metals, patent of the Russian Federation for an invention №2121518, C22B7/04, C22B7. 